\title{
Corrigendum
}

\section{Corrigendum to "A QFD-Based Evaluation Method for Business Models of Product Service Systems"}

\author{
Tianyang Li $\mathbb{D}^{1},{ }^{1}$ Ting He ${ }_{\mathbb{D}},{ }^{1}$ Zhongjie Wang, ${ }^{1}$ and Yufeng Zhang $\mathbb{D}^{2}$ \\ ${ }^{1}$ School of Computer Science and Technology, Harbin Institute of Technology, Harbin, Heilongjiang 150001, China \\ ${ }^{2}$ Birmingham Business School, University of Birmingham, Birmingham B15 2TT, UK \\ Correspondence should be addressed to Ting He; xuantinghe@hit.edu.cn \\ Received 3 September 2018; Accepted 5 September 2018; Published 27 September 2018 \\ Copyright (C) 2018 Tianyang Li et al. This is an open access article distributed under the Creative Commons Attribution License, \\ which permits unrestricted use, distribution, and reproduction in any medium, provided the original work is properly cited.
}

In the article titled "A QFD-Based Evaluation Method for Business Models of Product Service Systems" [1], the affiliation of the second author was incorrect. The corrected affiliation is as shown above.

\section{References}

[1] T. Li, T. He, Z. Wang, and Y. Zhang, "A QFD-based evaluation method for business models of product service systems," Mathematical Problems in Engineering, vol. 2016, Article ID 8532607, 15 pages, 2016. 


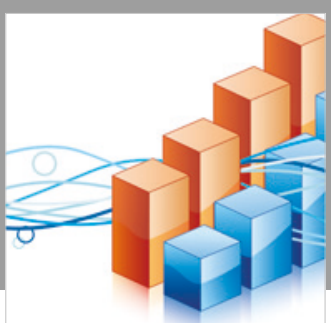

Advances in

Operations Research

\section{-n-m}
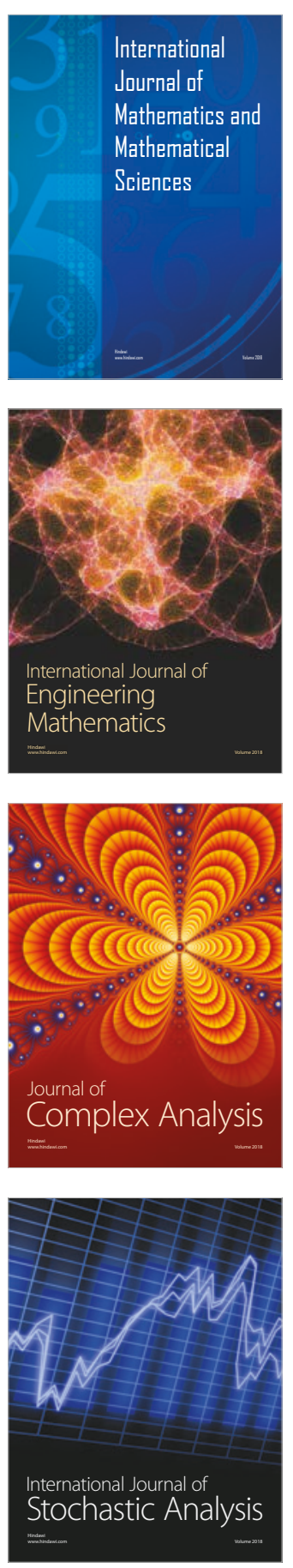
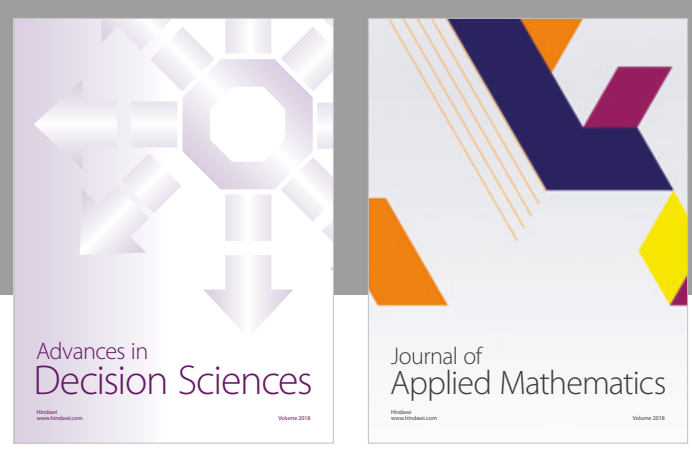

Journal of

Applied Mathematics
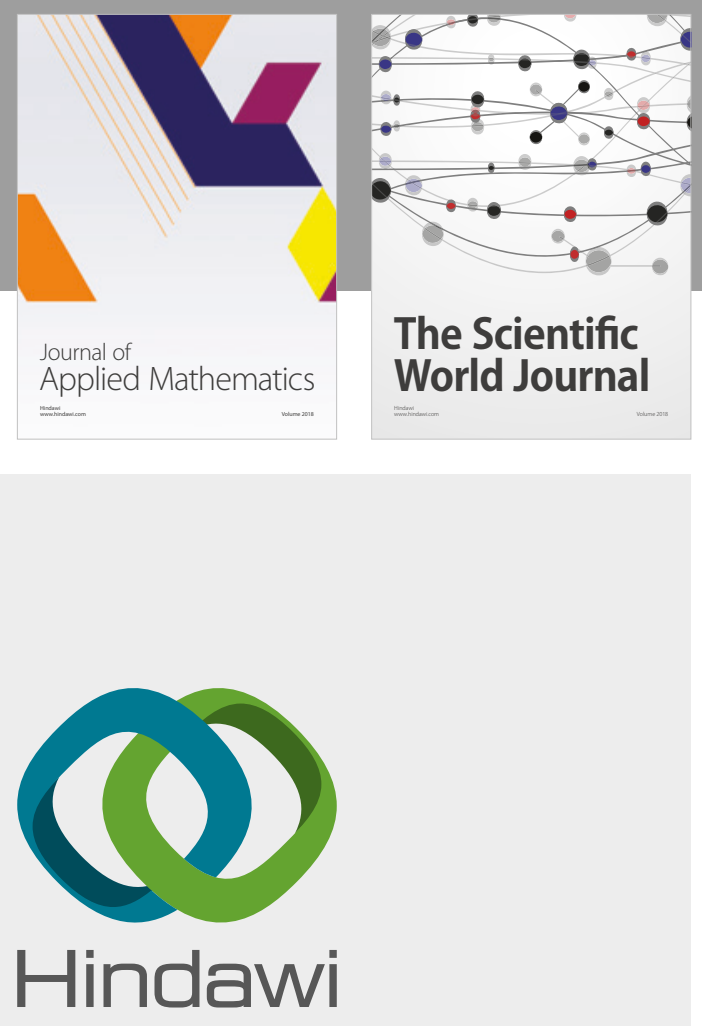

Submit your manuscripts at

www.hindawi.com

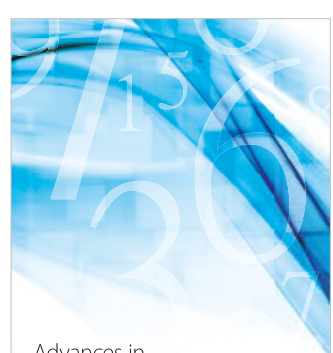

Advances in
Numerical Analysis
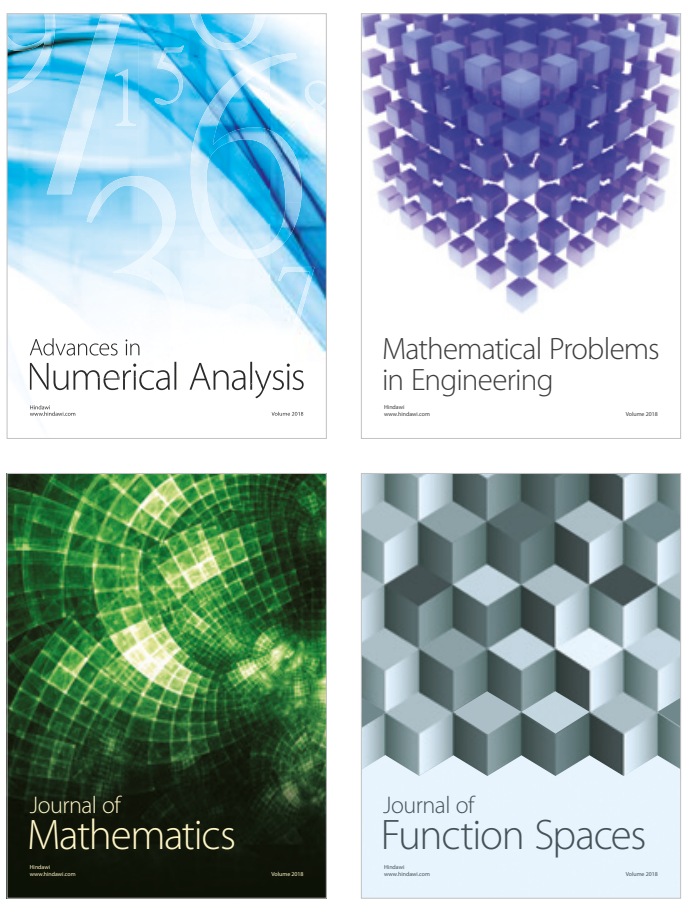

Mathematical Problems in Engineering

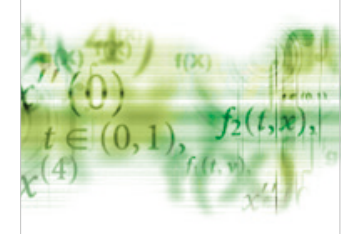

International Journal of

Differential Equations

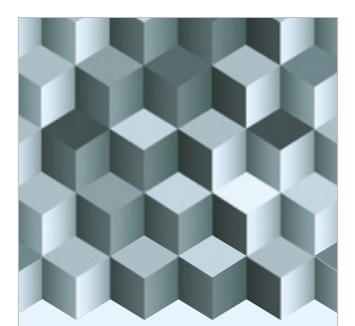

Journal of

Function Spaces

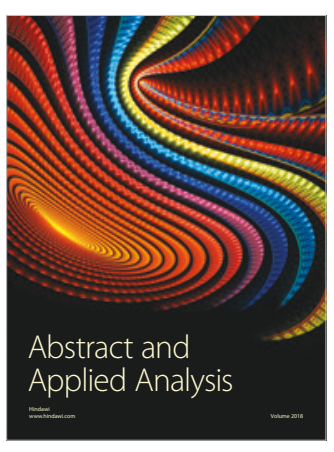

The Scientific

World Journal

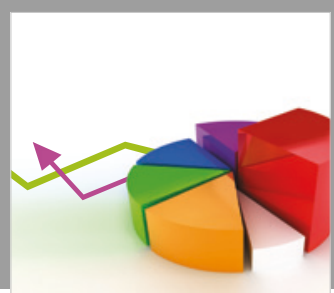

Journal of

Probability and Statistics
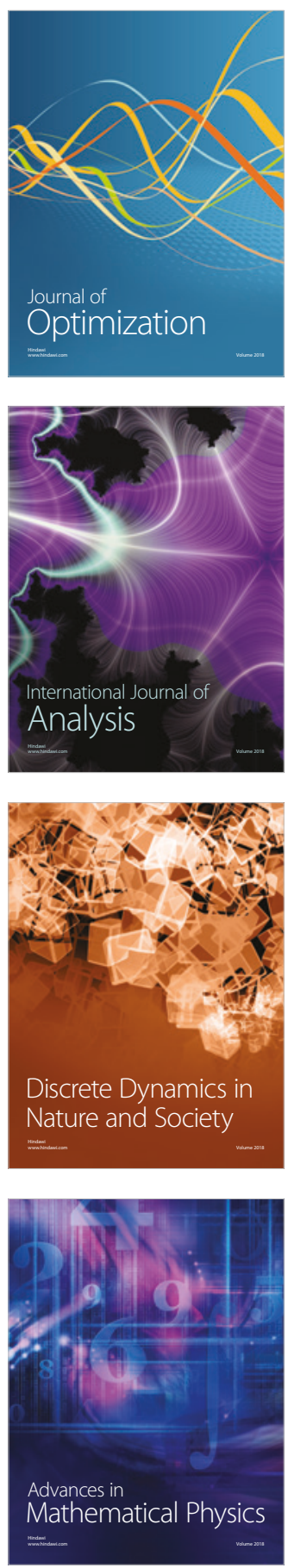